\title{
SISTEM PENDUKUNG KEPUTUSAN UNTUK MENENTUKAN LOKASI PEMBANGUNAN PERUMAHAN TYPE 36 M/S MENGGUNAKAN METODE WEIGHTED PRODUCT PADA PT.ROMEBY KASIH ABADI
}

\author{
Beni Andika, Muhammad Dahria, Erlina Siregar \\ Program Studi Sistem Informasi, STMIK Triguna Dharma
}

\begin{tabular}{|c|c|}
\hline Article Info & " ABSTRACT \\
\hline $\begin{array}{l}\text { Article history: } \\
\text { Received May } 31^{\text {th }}, 2019 \\
\text { Revised June } 12^{\text {th }}, 2019 \\
\text { Accepted Augs } 11^{\text {th }}, 2019\end{array}$ & $\begin{array}{l}\text { Saat ini PT. Romeby Kasih Abadi menggunakan cara manual untuk } \\
\text { memperoleh informasih yang akurat mengenai kelayakan lokasi barunya } \\
\text { yaitu dengan cara mengamati kondisi perumahan terdekat dan survey } \\
\text { kelokasi secara langsung. Hal ini tentu saja membutuhkan tenaga dan waktu } \\
\text { yang lama sebelum pihak PT. Romeby Kasih Abadi dapat memastikan } \\
\text { kelayakan suatu lokasi pembangunan Perumahan dikarenakan kurangnya }\end{array}$ \\
\hline $\begin{array}{l}\text { Keyword: } \\
\text { Sistem Pendukung Keputusan, } \\
\text { lokasi perumahan terbaik, } \\
\text { Weighted product, }\end{array}$ & $\begin{array}{l}\text { informasi yang akurat mengenai lokasi tersebut. } \\
\text { Dari uraian diatas perlu dibuat suatu program bantu untuk sistem } \\
\text { pendukung keputusan dalam pengambilan keputusan lokasi pembnagunan } \\
\text { perumahan yang terbaik. Program yang dibuat lebih bersifat untuk } \\
\text { mmembantu pihak PT. Romeby Kasih Abadi untuk mempercepat dalam } \\
\text { pengambilan keputusan sehingga dalam pengambilan keputusan lokasi } \\
\text { pembangunan perumahan yang terbaik dalam berjalan lebih cepat. } \\
\text { Hasil dari penelitian ini diharapkan dapat membantu pihak PT. Romeby } \\
\text { Kasih Abadi dalam menghasilkan laporan keputusan penentuan lokasi } \\
\text { pembangunan perumahan yang terbaik dengan lebih baik lagi dari sistem } \\
\text { yang telah berjalan sebelumnya. }\end{array}$ \\
\hline
\end{tabular}

Copyright $\odot 2019$ STMIK Triguna Dharma. All rights reserved.

\begin{tabular}{ll}
\hline First Author & \\
Nama & :Beni Andika \\
Kantor & :STMIK Triguna Dharma \\
Program Studi & :Sistem Informasi \\
E-Mail & :Beni @ trigunadharma.ac.id
\end{tabular}

\section{PENDAHULUAN}

PT.Romeby kasih abadi adalah perusahaan perseroan terbatas yang bidang usaha utamanya adalah pembangunan perumahan bagi masyarakat umum, dimana Tempat tinggal atau rumah adalah suatu kebutuhan primer yang bahkan seluruh masyarakat mengutamakan rumah dibandingkan dengan keperluan lainya. Oleh karena itu banyak pengembang melakukan pengolahan lahan untuk dijadikan perumahan dan property lainya.

PT.Romeby kasih abadi berusaha mengembangkan usahanya dengan cara membangun perumahan baru khususnya diwilayah kota medan yang lebih baik sehingga pemanfaatan lahan yang terbatas ditiap daerah menjadi lebih maksimal. PT.Romeby kasih abadi menambahkan kriteria-kriteria untuk lokasi barunya seperti jarak antara perumahaan dengan pasar tradisional, jarak dengan jalan utama tidak boleh terlalu jauh, lokasi perumahan harus disesuaikan dengan tingkat kepadatan penduduk.

Saat ini PT.Romeby kasih abadi masih menggunakan cara manual untuk memperoleh informasi yang akurat mengenai kelayakan lokasi barunya yaitu dengan mengamati kondisi perumahan terdekat dan survey kelokasi secara langsung. Hal ini tentu saja membutuhkan tenaga dan waktu yang lama sebelum pihak perusahaan memastikan kelayakan suatu lokasi untuk membuka membangun perumahan dikarenakan kurangnya informasi yang akurat mengenai lokasi tersebut. Oleh karena itu dibutuhkan suatu sistem yang dapat membantu dalam pengambilan keputusan lokasi pembangunan perumahan yang terbaik.

Sistem Pendukung Keputusan (SPK) adalah sistem berbasis komputer interaktif, yang membantu para pengambil keputusan untuk menggunaka data yang berbagai model untuk memecahkan masalah-masalah yang tidak terstruktur. Berdasarkan permasalahan yang muncul maka diperlukan sistem pendukung 
keputusan yang memiliki beberapa kriteria yang dijadikan pertimbangan untuk pengambilan keputusan, salah satunya iyalah metode Weighted product, metode ini merupakan salah satu metode yang bisa membantu pengambilan keputusan terhadap beberapa alternatif keputusan yang harus diambil dengan beberapa kriteria yang menjadi pertimbangan.

\section{Landasan Teori}

\subsection{Sistem Pendukung Keputusan}

Sistem merupakan kumpulan elemen yang saling berkorelasi satu dengan yang lainnya guna untuk mencapai tujuan tertentu.

\subsection{Metode weighted product}

Menurut basyahyaib (Dalam Marsono, dkk ) "metode Weighted Product (WP) merupakan sebuah metode pengambilan keputusan dengan cara perkalian dalam menghubungkan suatu rating atribut dimana setiap rating atribut harus dipangkatkan dulu dengan bobot atribut yang bersangkutan. Bobot untuk atribut, berfungsi sebagai pangkat positif dalam proses perkalian antar atribut sementara rating atribut berfungsi sebagai pangkat negatif bagi atribut biayaProses tersebut sama halnya dengan proses normalisasi. Dalam penentuan nilai kepentingan atau bobot pada aplikasi SPK sebagai alat bantu, pencarian nilai bobot atribut menggunakan penilaian secara subyektif yaitu pensklaanya dari 1 sampai 4 berdasarkan penilaian disesuaikan dengan tingkat sumbangan dari pengguna. Metode Weighted Product memerlukan proses normalisasi karena metode ini mengalikan hasil-hasil penilaian setiap atribut. Hasil perkalian tersebut belum bermakna jika belum dibandingkan (dibagi) dengan nilai standart. Bobot untuk atribut manfaat berfungsi sebagai pangkat positif dalam proses perkalian, sementara bobot biaya berfungsi sebagai negatif.

2.2.1 langkah-langkah metode $w p$

1 Menentukan rating kecocokan nilai alternatif dengan cara mengalikan seluruh kriteria dengan alternatif.

2 Hasil perkalian tersebut dijumlahkan untuk menghasilkan nilai (V) untuk setiap alternatif.

3 Mencari nilai alternatif ideal .

4 Membagi nilai (V) bagi setiap alternatif dengan nilai standart (V(A*)) yang menghasilkan A

5 Menentukan nilai alternatif yang paling tinggi sebagai alternatif terbaik yang akan menjadi keputusan.

Berikut ini adalah rumus untuk melakukan menormalisasi setiap nilai alternatif (nilai vektor) yaitu sebagai berikut:

$$
S_{i=} \prod_{j=1}^{n} X_{i j} w j
$$

Dimana:

$S_{i}=$ nilai alternatif

$\mathrm{n}$ = banyaknya kriteria

$X_{i j}=$ nilai dari setiap baris dan kolom

$\mathrm{Wj}=$ nilai atribut yang dimiliki dari setiap criteria

\subsection{Metode penelitian}

Dalam pembahasan masalah terdapat 5 metode penelitian yang bisa digunakan:

1. Library research (penelitian pustaka)

Dalam penelitian pustaka dilakukan dengan cara membaca buku-buku diperpustakaan, jurnal-jurnal dan pencarian melalui internet yang dapat mendukung dalam penyelesaian penelitian ini.

2. Pengumpulan data

a. Observasi

Observasi merupakan tehnik pengumpulan data dengan melakukan tinjauan langsung ketempat studi kasus dimana akan dilakukan penelitian dalam hal observasi penelitian dilakukan di PT.Romeby Kasih Abadi.

b. Wawancara

Pengumpulan data dengan cara mempelajari dan mencatat langsung segala hal-hal yang berkaitan dengan masalah dan yang diperlukan di PT.Romeby Kasih Abadi.

3. Analisis dan perancangan 
Setelah data-data diperoleh maka langkah berikutnya adalah menganalisa untuk menyelesaikan masalah-masalah yang ada. Perancangan dilakukan setelah menganalisa masalah sehingga masalah sehingga gambaran atau rancangan sistem mudah dilakukan.

4. Implementasi

Implementasi merupakan tahap untuk membangun perangkat lunak dengan menggunakan metode Weighted Product. Sistem dibangun dengan berpedoman pada konsep-konsep yang sudah ditentukan pada tahap sebelumnya.

\subsection{Analisis Permasalahan}

Saat ini rumah merupakan kebutuhan primer oleh setiap manusia. Sehingga hal tersebut benar-benar sangat dibutuhkan oleh masyarakat. Oleh sebab itu maka pihak property PT.Romeby kasih abadi sebagai pengembang melakukan penbangunan perumahan sebanyak-banyaknya untuk dapat menyediakan kebutuhan konsumen saat ini. Berdasarkan hal tersebut maka pihak property PT.Romeby terlebih dahulu memilih beberapa tempat sebagai alternatif diantaranya yaitu, Medan tuntungan, Tanjung selamat, Katalimbaru, Tanjung anom dan Sunggal, dari kelima alternatif tersebut nantinya akan dipilih satu lokasi terbaik yang akan dijadikan tempat untuk membangun perumahan.

Sistem Pendukung Keputusan (SPK) adalah sistem berbasis komputer interaktif, yang membantu para pengambil keputusan untuk menggunakan data dan berbagai model untuk memecahkan masalahmasalah yang tidak terstruktur. Berdasarkan permasalahan yang muncul maka diperlukan sistem pendukung keputusan yang memiliki beberapa kriteria yang dijadikan pertimbangan untuk pengambilan keputusan. Untuk itu maka dibutuhkan sebuah metode untuk menentukan lokasi pembangunan terbaik untuk membangun perumahan PT Romeby kasih abadi hal ini diperlukan agar dapat membantu pihak PT. Romeby kasih abadi dalam menentukan lokasi terbaik dalam membangun perumahan.

Oleh karena itu maka digunakan metode weighted product, dalam melakukan penyelesaian kasus tersebut.

\subsection{Algoritma sistem}

Algoritma sistem merupakan urutan langkah-langkat yang dilakukan dalam penyelesaian suatu masalah berdasarkan elemen-elemen yang saling integrasi dengan dituangkan kedalam kalimat untuk mencapai tujuan yang telah ditetapkan sehingga algoritma sistem yang jelas dan teratur sangat diperlukan dalam penyelesaian perancangan perangkat lunak. Algoritma sistem juga merupakan sebuah tahapan yang dilakukan untuk menentukan lokasi pembangunan perumahan terbaik dengan menggunakan metode weighted product

Tabel 3.1 Nilai Kriteria Akses Transportasi(C1)

\begin{tabular}{|c|c|c|c|}
\hline No & Akses transportasi & Nilai & Keterangan \\
\hline 1 & Dekat dari jalan raya & 5 & Sangat penting \\
\hline 2 & Jauh dari jalan raya & 4 & penting \\
\hline
\end{tabular}

Tabel 3.2 Nilai Kriteria Struktur Tanah (C2)

\begin{tabular}{|c|c|c|c|}
\hline No & Struktur tanah & Nilai & Keterangan \\
\hline 1 & Pemukiman & 5 & Sangat penting \\
\hline 2 & Irigasi & 4 & penting \\
\hline 3 & Industri & 3 & Cukup penting \\
\hline
\end{tabular}

Tabel 3.3 Nilai Kriteria Kepadatan Penduduk (C3)

\begin{tabular}{|c|c|c|c|}
\hline No & Kepadatan penduduk & Nilai & Keterangan \\
\hline 1 & $\geq 10000 \mathrm{jiwa} / \mathrm{Km}^{2}$ & 1 & Sangat tidak penting \\
\hline 2 & $7000-9000 \mathrm{jiwa} / \mathrm{Km}^{2}$ & 2 & Tidak penting \\
\hline 3 & $5000-6000 \mathrm{jiwa} / \mathrm{Km}^{2}$ & 3 & Cukup penting \\
\hline 4 & $3000-4000 \mathrm{jiwa} / \mathrm{Km}^{2}$ & 4 & penting \\
\hline 5 & $\leq 3000 \mathrm{jiwa} / \mathrm{Km}^{2}$ & 5 & Sangat penting \\
\hline
\end{tabular}

Tabel 3.4 Nilai Kriteria Harga Tanah (C4)

\begin{tabular}{|c|c|c|c|}
\hline No & Harga tanah & Nilai & Keterangan \\
\hline 1 & Rp .375000,-/ Meter & 5 & Sangat penting \\
\hline 2 & Rp .400000,-/ Meter & 4 & Penting \\
\hline 3 & Rp .425000,-/ Meter & 3 & Cukup penting \\
\hline 4 & Rp .450000,-/ Meter & 1 & Sangat Tidak penting \\
\hline
\end{tabular}


Tabel 3.5 Nilai Kriteria Jarak aksesibilitas (C5)

\begin{tabular}{|c|c|c|c|}
\hline No & Jarak aksesibilitas & Nilai & Keterangan \\
\hline 1 & $\geq 25$ Kilo Meter & 1 & Sangat Tidak penting \\
\hline 2 & 15Kilo Meter- 20 Kilo Meter & 2 & Tidak penting \\
\hline 3 & 11 Kilo Meter- 15 Kilo Meter & 3 & Cukup penting \\
\hline 4 & 5Kilo Meter- 10 Kilo Meter & 4 & Penting \\
\hline 5 & $\leq 5$ Kilo Meter & 5 & Sangat penting \\
\hline
\end{tabular}

Tabel 3.6 Nilai Kriteria Status Tanah(C6)

\begin{tabular}{|c|c|c|c|}
\hline No & Status tanah & Nilai & Keterangan \\
\hline 1 & $\begin{array}{c}\text { Sertifikat dan Surat } \\
\text { keterangan dari camat }\end{array}$ & 5 & Sangat penting \\
\hline 2 & Sertifikat & 4 & Penting \\
\hline 2 & Surat keterangan dari camat & 3 & Sangat Tidak penting \\
\hline 3 & Tidak ada surat izin & 1 & \\
\hline
\end{tabular}

\subsection{Penilaian Setiap Alternatif}

Setelah selesai menentukan kriteria maka langkah selanjutnya adalah melakukan penilaian pada setiap alternatif. Dalam hal ini 5 alternatif yang akan dilakukan penilaian dapat dilihat pada tabel 3.6 berikut ini.

Tabel 3.7 Penilaian Dari Setiap Alternatif Dalam Bentuk Keterangan

\begin{tabular}{|c|c|c|c|c|c|c|c|}
\hline \multirow{2}{*}{ No } & \multirow{2}{*}{ Alternatif } & \multicolumn{6}{|c|}{ Nama kriteria } \\
\hline & & $\mathrm{C1}$ & $\mathrm{C2}$ & $\mathrm{C3}$ & C4 & $\mathrm{C5}$ & C6 \\
\hline 1 & Sunggal & $\begin{array}{l}\text { Dekat } \\
\text { jalan } \\
\text { raya }\end{array}$ & Industri & $\begin{array}{l}3000 \\
\text { jiwa/km² }\end{array}$ & $\begin{array}{l}\mathrm{Rp} \\
000,-\end{array}$ & $\begin{array}{l}\text { 10kilo } \\
\text { meter }\end{array}$ & $\begin{array}{l}\text { Sertifikat } \\
\text { \&SK } \\
\text { camat }\end{array}$ \\
\hline 2 & $\begin{array}{l}\text { Tanjung } \\
\text { anom }\end{array}$ & $\begin{array}{l}\text { Jauh } \\
\text { jalan } \\
\text { raya }\end{array}$ & Industri & $\begin{array}{l}6000 \\
\text { jiwa/km² }\end{array}$ & $\begin{array}{l}\mathrm{Rp} \\
000,-\end{array}$ & $\begin{array}{l}15 \mathrm{kilo} \\
\text { meter }\end{array}$ & Sertifikat \\
\hline 3 & Kutalimbaru & $\begin{array}{l}\text { Dekat } \\
\text { jalan } \\
\text { raya }\end{array}$ & Pemukiman & $\begin{array}{l}3000 \\
\text { jiwa/km² }\end{array}$ & $\begin{array}{l}\mathrm{Rp}_{000,-} \\
075\end{array}$ & $\begin{array}{l}\text { 10kilo } \\
\text { meter }\end{array}$ & Sertifikat \\
\hline 4 & $\begin{array}{l}\text { Tanjung } \\
\text { selamat }\end{array}$ & $\begin{array}{l}\text { Dekat } \\
\text { jalan } \\
\text { raya }\end{array}$ & Irigasi & $\begin{array}{l}2000 \\
\text { jiwa/km² }\end{array}$ & $\begin{array}{l}\mathrm{Rp} \\
425000,-\end{array}$ & $\begin{array}{l}\text { 20kilo } \\
\text { meter }\end{array}$ & $\begin{array}{l}\text { Tidak } \\
\text { ada surat } \\
\text { izin }\end{array}$ \\
\hline 5 & $\begin{array}{l}\text { Medan } \\
\text { tuntungan }\end{array}$ & $\begin{array}{l}\text { Jauh } \\
\text { jalan } \\
\text { raya }\end{array}$ & Pemukiman & $\begin{array}{l}10000 \\
\text { jiwa/km² }\end{array}$ & $\begin{array}{l}\mathrm{Rp} \\
450000,-\end{array}$ & $\begin{array}{l}25 \mathrm{kilo} \\
\text { meter }\end{array}$ & $\begin{array}{c}\text { SK } \\
\text { camat }\end{array}$ \\
\hline
\end{tabular}

Tabel 3.8 Penilaian Dari Setiap Alternatif Dalam Bentuk Keterangan

\begin{tabular}{|l|l|c|c|c|c|c|c|}
\hline \multirow{2}{*}{ No } & \multirow{2}{*}{ Alternatif } & \multicolumn{7}{|c|}{ Nama Kriteria } \\
\cline { 3 - 8 } & & C1 & C2 & C3 & C4 & C5 & C6 \\
\hline 1 & Sunggal & 5 & 3 & 4 & 5 & 4 & 5 \\
\hline 2 & Tanjung anom & 4 & 3 & 3 & 4 & 3 & 4 \\
\hline 3 & Kutalimbaru & 5 & 5 & 4 & 5 & 4 & 4 \\
\hline 4 & Tanjung selamat & 5 & 4 & 5 & 3 & 2 & 1 \\
\hline 5 & Medan tuntungan & 4 & 5 & 1 & 1 & 1 & 3 \\
\hline
\end{tabular}

Tabel 3.9 Nilai Bobot Kriteria Metode Weighted Product $(\mathrm{Wj})$

\begin{tabular}{|c|c|c|c|}
\hline No & Nama kriteria & $\begin{array}{c}\text { Nilai bobot } \\
(\mathbf{W j})\end{array}$ & Keterangan \\
\hline 1 & Akses transportasi $(\mathrm{C} 1)$ & 0.15 & Benefit \\
\hline 2 & Struktur tanah(C2) & 0.25 & Benefit \\
\hline 3 & Kepadatan pendudukan(C3) & 0.15 & Benefit \\
\hline
\end{tabular}




\begin{tabular}{|c|c|c|c|}
\hline 4 & Harga tanah (C4) & 0.15 & Cost \\
\hline 5 & Jarak aksesibilitas(C5) & 0.05 & Benefit \\
\hline 6 & Status tanah (C6) & 0.25 & Benefit \\
\hline
\end{tabular}

Dari 6 kriteria tersebut diatas bernilai positif untuk atribut keuntungan /benefit (C1,C2.C3,C5,C6)

dan bernilai negatif untuk atribut biaya (C4)

\subsubsection{Menormalisasi Setiap Nilai Alternatif (Nilai Vektor)}

Nilai Vektor untuk Daerah Sunggal

$\mathrm{S} 1=\left(5^{0.15}\right) *\left(2^{0.25}\right) *\left(4^{0.15}\right) *\left(5^{-0.15}\right) *\left(4^{0.05}\right) *\left(5^{0.25}\right)=2.596778$

Nilai Vektor untuk Daerah Tanjung Anom

$\mathrm{S} 2=\left(4^{0.15}\right) *\left(3^{0.25}\right) *\left(3^{0.15}\right) *\left(4^{-0.15}\right) *\left(3^{0.05}\right) *\left(4^{0.25}\right)=2.318567$

Nilai Vektor untuk Daerah Kutalimbaru

$\mathrm{S} 3=\left(5^{0.15}\right) *\left(5^{0.25}\right) *\left(4^{0.15}\right)^{*}\left(5^{-0.15}\right) *\left(4^{0.05}\right) *\left(4^{0.25}\right)=2.790419$

Nilai Vektor untuk Daerah Tanjung Selamat

$\mathrm{S} 4=\left(5^{0.15}\right) *\left(4^{0.25}\right) *\left(5^{0.15}\right) *\left(3^{-0.15}\right) *\left(2^{0.05}\right) *\left(1^{0.25}\right)=2.012284$

Nilai Vektor untuk Daerah Medan Tuntungan

$\mathrm{S} 5=\left(4^{0.15}\right) *\left(5^{0.25}\right) *\left(1^{0.15}\right) *\left(1^{-0.15}\right) *\left(1^{0.05}\right) *\left(3^{0.25}\right)=2.422879$

\subsubsection{Menghitung Nilai Bobot Preferensi Pada Setiap Alternatif}

$$
\text { Rumus Preferensi }=\frac{\mathrm{S}}{(\mathrm{S1}+\mathrm{S2}+\mathrm{Sa}+\mathrm{S4}+\mathbf{5 5})}
$$

Nilai Preferensi Vi untuk Daerah Sunggal

$$
2.596778
$$

$\frac{2.596778}{(2.596778+2.318567+2.790419+(2.012284)+2.422879)}=0.213886$

Nilai Preferensi Vi untuk Daerah Tanjung Anom 2.318567

$\frac{2.318567}{(2.596778+2.318567+2.790419+(2.012284)+2.422879)}=0.190971$

Nilai Preferensi Vi untuk Daerah Kutalimbaru

$\frac{2.790419}{(2.596778+2.318567+2.790419+(2.012284)+2.422879)}=0.229836$

Nilai Preferensi Vi untuk Daerah Tanjung Selamat

$\frac{2.012284}{(2.596778+2.318567+2.790419+(2.012284)+2.422 .979)}=0.165744$

Nilai Preferensi Vi untuk Daerah Medan Tuntungan

$\frac{2.422879}{(2.596778+2.318567+2.790419+(2.012284)+2.422879)}=0.199563$

\subsubsection{Perangkingan}

Setelah didapatkan hasilnya maka langkah terakhir adalah perangkingan

Tabel 3.10 Perangkingan Metode Weighted product

\begin{tabular}{|c|c|c|c|}
\hline No & Nama alternatif & Nilai bobot preferensi & Keterangan \\
\hline 1 & Sunggal & 0.213886 & Rangking 2 \\
\hline 2 & Tanjung anom & 0.190971 & Rangking 4 \\
\hline 3 & Kutalimbaru & 0.229836 & Rangking 1 \\
\hline 4 & Tanjung selamat & 0.165744 & Rangking 5 \\
\hline 5 & Medan tuntungan & 0.199563 & Rangking 3 \\
\hline
\end{tabular}

\section{Use Case diagram}

Use case diagram deskripsi fungsi dari sebuah sistem dari perspektif pengguna. Use case bekerja dengan cara mendeskripsikan tipikal interaksi antara user (pengguna) sebuah sistem dengan sistemnya sendiri melalui sebuah cerita bagaimana sebuah sistem dipakai. Berikut ini adalah perancangan use case untuk admin dari sebuah sistem pendukung keputusan. 


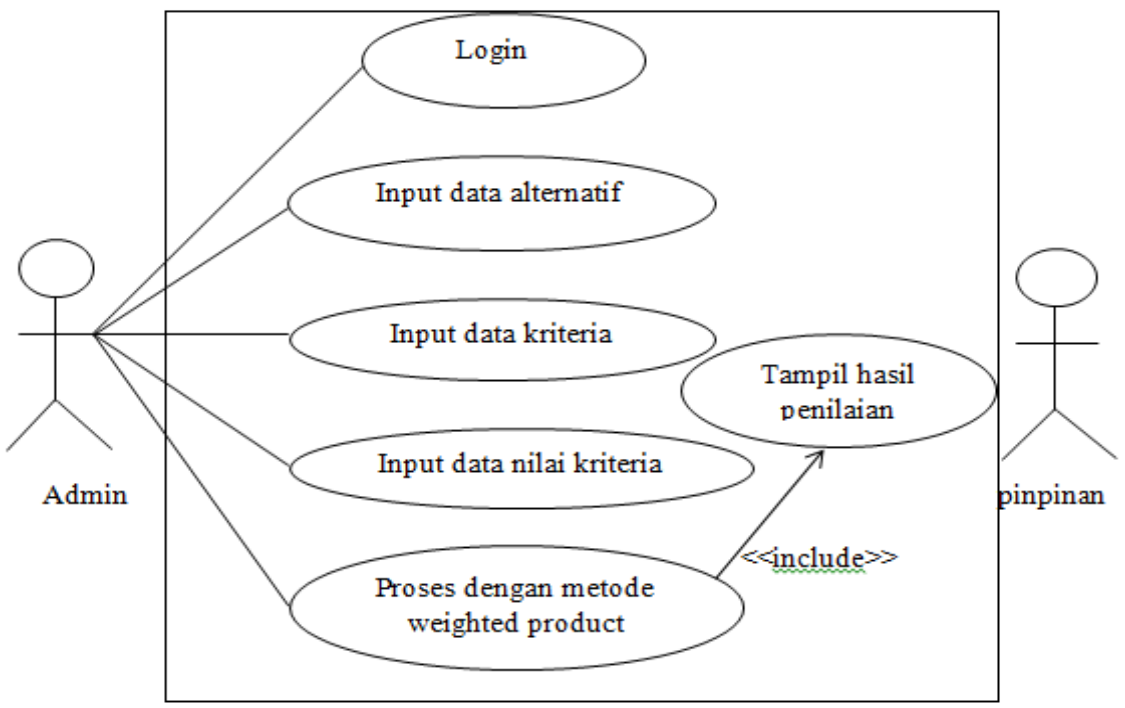

Gambar 3.2 Use Case Diagram

\section{Implementasi dan pembahasan}

1. Form Login

Form Login adalah form yang akan tampil pertama kali, pada form ini admin diharuskan mengisi username dan password. Adapun tampilan form login adalah seperti gambar berikut ini.

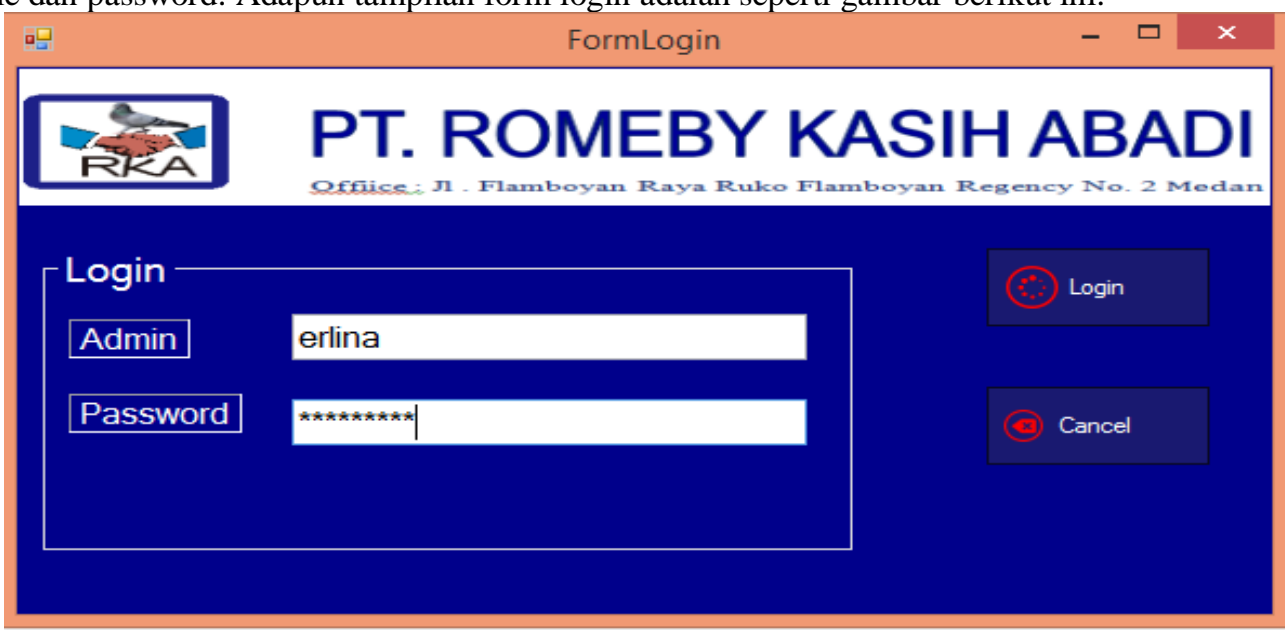

Gambar 4.1 Form Login

2 Form menu utama

Setelah user berhasil login maka sistem akan menampilkan menu utama seperti yang terlihat pada gambar 4.2 dibawah ini:

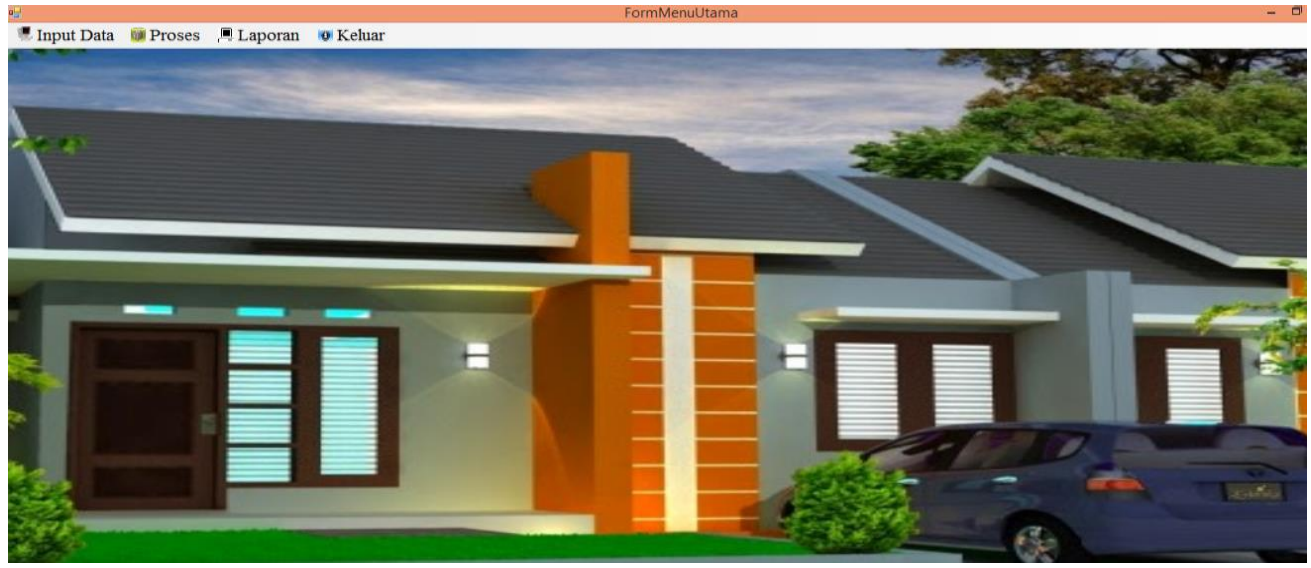

Gambar 4.2 Tampilan Form Menu Utama 


\section{Form Data Alternatif}

Form ini berisikan tentang data alternatif yang berfungsi sebagai media dalam memasukan data alternatif yang akan dilakukan penilaian. Kelebihan dari form ini adalah dapat mengolah data alternatif secara update dengan database. Form data alternatif dapat dilihat pada gambar 4.3 dibawah ini.

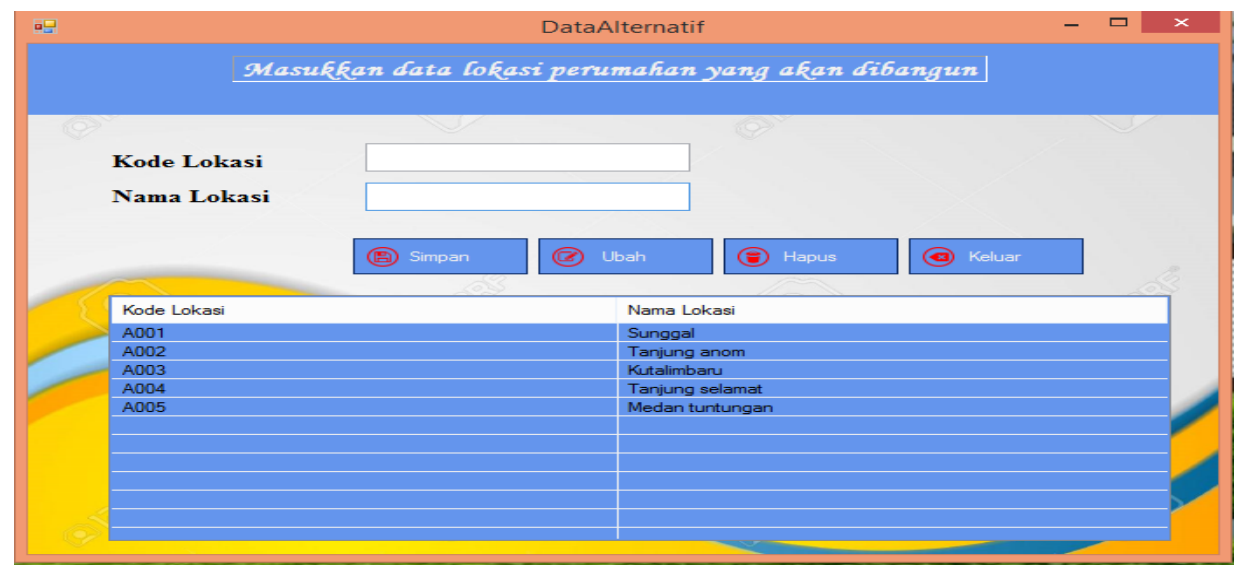

\section{Form kriteria}

Gambar 4.3 Tampilan Data alternatif

Tampilan nilai kriteria ini berisikan tentang data nilai kriteria. Tampilan form dapat dilihat pada gambar 4.4 dibawah ini

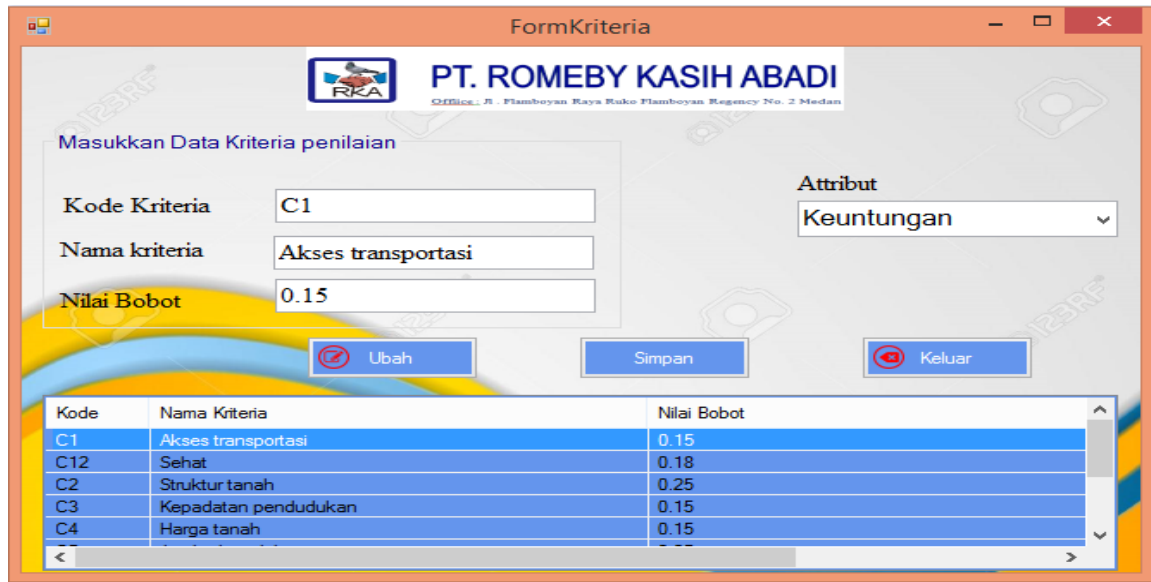

Gambar 4.4 Tampilan Form kriteria

\section{Form Data penilaian}

Form ini digunakan untuk menampilkan penilaian terhadap alternatif, didalam Form ini proses perhitungan dilakukan dengan menggunakan Metode WP. Adapun tampilan dapat dilihat pada gambar 4.5dibawah ini.

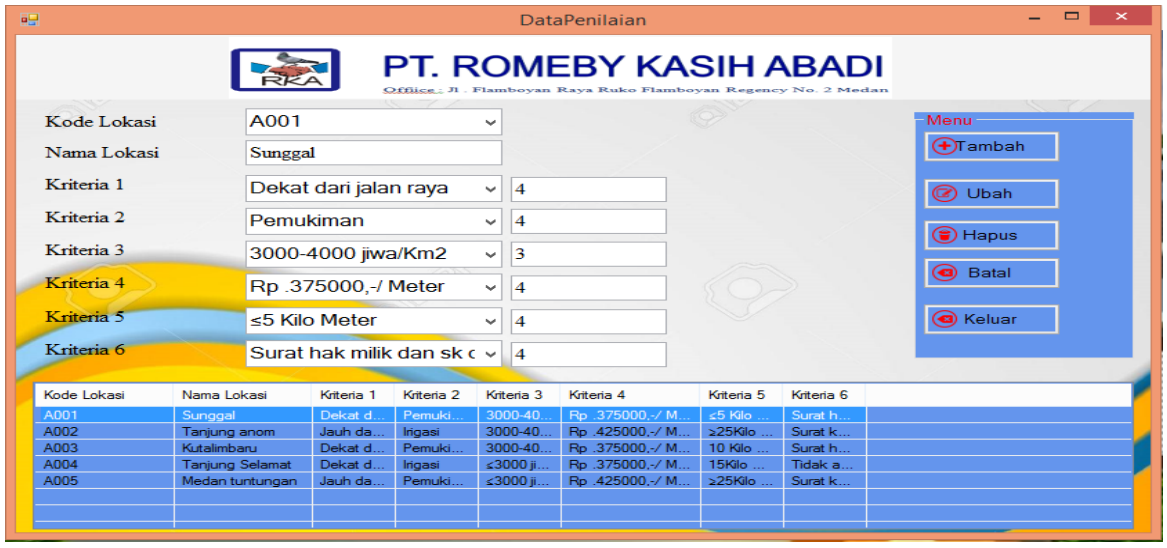

Gambar 4.5 Tampilan Form Penilaian 


\section{Form Normalisasi}

Form normalisasi adalah form yang digunakan untuk menampilkan proses normalisasi. Setelah proses normalisasi selesai maka selanjutnya adalah proses preferensi. Proses preferensi adalah proses akhir dari perhitugan metode weighted product. Berikut tampilan Form normalisasi dapat dilihat pada form 4.6 dibawah ini.

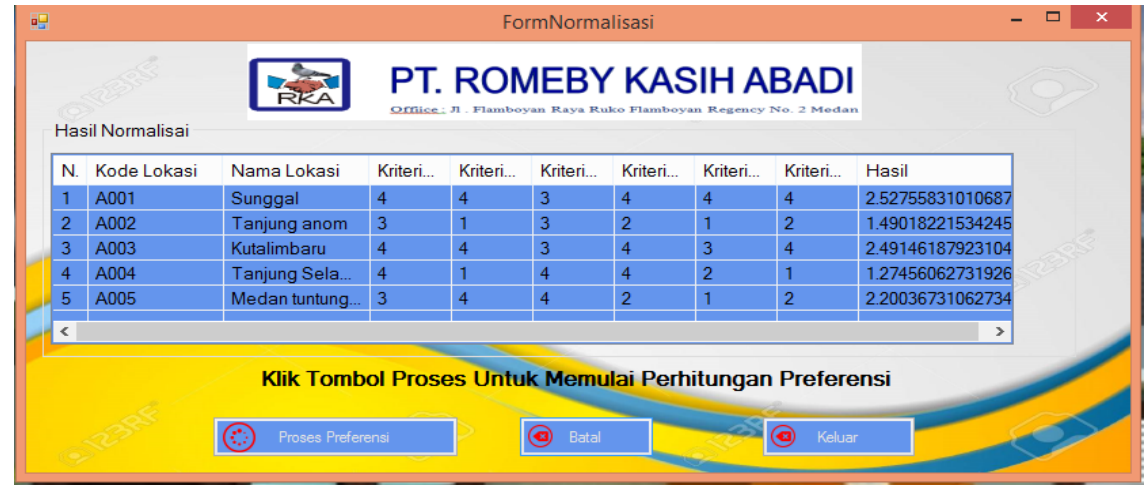

\section{Laporan Hasil Keputusan}

Gambar 4.6 Tampilan Form Normalisasi

Setelah proses perhitungan selesai maka sistem akan menampilkan hasil laporan Sistem Pendukung Keputusan dalam menentukan lokasi pembangunan perumahan yang terbaik dengan metode weighted product. Berikut adalah tampilan laporan hasil keputusan:

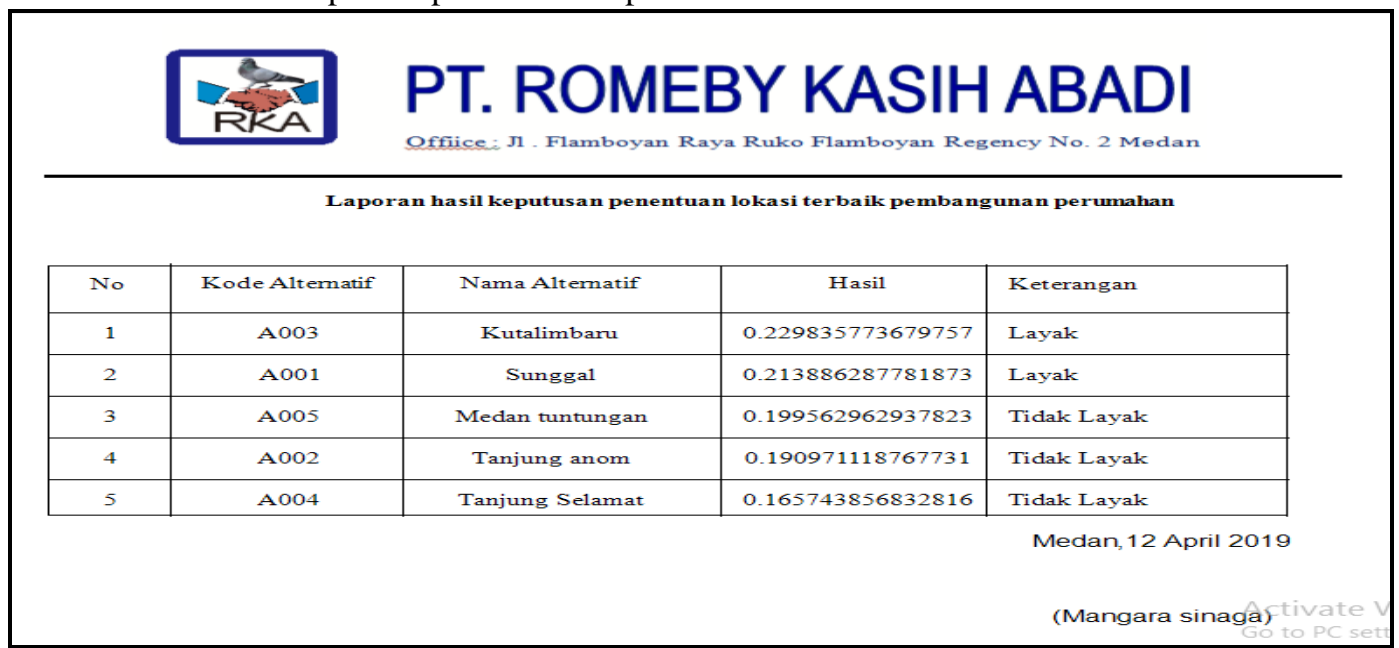

Gambar 4.7 Tampilan Laporan hasil Keputusan

\subsection{Kelebihan dan kelemahan sistem}

Adapun kelebihan dari sistem yang telah dibangun adalah sebagai berikut:

1. Memperluas kemampuan pengambilan keputusan dalam memproses data/ informasi untuk mengambil keputusan

2. Menghemat waktu yang dibutuhkan untuk memecahkan masalah, terutama berbagai masalah yang sangat kompleks dan tidak terstruktur.

3. Menghasilkan solusi dengan lebih cepat dan hasilnya dapat diandalkan.

4. Mampu memberikan berbagai alternatif dalam pengambilan keputusan, meskipun seandainya sistem ini tidak mampu memecahkan masalah yang dihadapi oleh pengambil keputusan, namun dapat digunakan stimulan dalam memahami persoalan.

5. Memperkuat keyakinan pengambilan keputusan terhadap keputusan yang diambilnya

6. Memberikan keuntungan kompetitif bagi organisasai secara keseluruhan dengan penghemat waktu, tenaga dan biaya

Ada kelebihan pasti ada juga kelemahanya adapun kelemahan dari sistem ini adalah sebagai berikut:

1. Sistem ini dirancang untuk membantu / mendukung pengambilan keputusan dengan mengelola informasi dan data yang diperlukan bukan untuk mengambil alih pengambilan keputusan

2. Harus selalu diadakan perubahan secara berkala untuk menyesuaikan dengan keadaan lingkungan yang terus berubah agar sistem tersebut agar selalu up to date

3 Tidak mendukung jaringan LAN dan Internet 


\subsection{Kesimpulan} disimpulkan:

Dari pembahasan pada bab-bab sebelumnya, beberapa berikut ini kesimpulan yang dapat

1. Sistem pendukung keputusan untuk menentukan lokasi terbaik dalam untuk pembangunan perumahan dimulai dengan pembobotan kriteria, kemudian perhitungan dan penilaian, perhitungan nilai total dan selanjutnya perhitungan penentuan rangking

2. Mengimplementasikan aplikasi proses pengambilan keputusan dalam penentuan lokasi pembangunan perumahan dengan kriteria kepadatan penduduk, akses transportasi, status tanah, perijinan, harga tanah, dan jarak aksesibilitas, dapat membantu menentukan lokasi pembangunan perumahan akan lebih cepat dan akurat.

\subsection{Saran}

Agar pengembang sistem kedepanya dapat dirancang dengan pengembangan yang lebih meningkat khususnya pada sistem pendukung keputusan dengan menggunakan metode Weighted product (WP) beberapa berikut ini saran yang dapat diberikan:

1. Perangkat lunak sistem pendukung keputusan ini dapat dikembangkan seiring perkembangan kebutuhan pengguna sistem sehingga dapat meningkatkan kinerja sistem.

2. Sistem ini dirancang untuk membantu pihak manajemen dalam proses pengambilan keputusan dengan menggunakan metode WP agar lebih akurat.

3. Mengimplementasikan aplikasi yang dirancang dengan menggunakan visual basic 2008 dan Microsoft Acces 2010

\section{UCAPAN TERIMA KASIH}

Terima kasih kepada dosen pembimbing Bapak Beni Andika,S.T.,M.Kom. Jaka Prayudha,S.Kom.,M.kom., beserta pihak-pihak lainnya yang mendukung penyelesaian jurnal skripsi ini.

\section{DAFTAR PUSTAKA}

Dicky Nofriansyah,S.kom .M.Kom 2015.Konsep Data Mining vs Sistem Pendukung Keputusan.Yogyakarta .Cv Budi utama.

Dicky Nofriansyah,S.kom .M.Kom \& Prof .Dr.Sarjon Defit, S.Kom ,M.Sc.2017.MULTI CRITERIA DECISION MAKING (MCDM) pada Sistem Pendukung Keputusan -Weight Product (WP).Deepublislish.

Jusuf Wahyudi1, Ferry Hari Utami2. SISTEM PAKAR DIAGNOSA PENYAKIT PADA AYAM DENGAN METODE FORWARD CHAINING. Vol. 7, no. 2, 2011.

Khairina, Dyna Marisa. "Analytical Hierarchy Process Sebagai Pendukung Keputusan (Decision Support) Pemilihan Lokasi Pembangunan Rumah Kos Untuk Karyawan.” Jurnal Informatika Mulawarman, vol. 7, no. 3, 2012, pp. 75-81.

Kusrini, M.kom 2007.Konsep dan Aplikasi Sistem Pendukung Keputusan .Yogyakarta .Andi

Marsono, Ahmad Fitri Boy, Darjat Saripurna, Saiful Nur Arif. "Sistem Pendukung Keputusan Penentuan Pemasaran Rumah Berdasarkan Analisa Pelanggan Dengan Metode Weighted Product (WP)." Program Studi Sistem Informasi STMIK Triguna Dharma, vol. 15, no. 2, 1978, pp. 109-19.

Nasyuha, Asyahri Hadi, et al. Analisa Perbandingan Metode Wp Dan Mfep Dalam Pemilihan Merk Pakaian Terbaik. 1978.

Panggabean, E. (2015). SISTEM PENDUKUNG KEPUTUSAN PENENTUAN LOKASI PERUMAHAN IDEAL MENGGUNAKAN METODE FUZZY SIMPLE ADDITIVE WEIGHTING Erwin Panggabean Program Studi Sistem Informasi STMIK Sisingamangaraja XII Medan Sumatera Utara-Indonesia email : $\operatorname{Er}, I V(1), 12-17$.

Rosa A.S.M.Shalahuddin.2018.Rekayasa Perangkat Lunak (Terstruktur dan Berorientasi objek).INFORMATIKA

Sugiharti, Endang, et al. "Perancangan Aplikasi Surat Masuk Dan Keluar Pada PT. Angkasa Pura 1 Semarang." Scientific Journal of Informatics, vol. 1, no. 1, 2014, pp. 39-52.

Westriningsih 2010. Microsoft office 2010.Semarang .C.V Andi.

[1] Yasin Verdi, S.Kom., M. Kom.2012 Rekayasa Perangkat Lunak berorientasi objek.Jakarta, Mitra Wacana Media 